OESOPHAGUS

\title{
Cognitive modulation of the cerebral processing of human oesophageal sensation using functional magnetic resonance imaging
}

\author{
L J Gregory, L Yágüez, S C R Williams, C Altmann, S J Coen, V Ng, M J Brammer, D G Thompson, \\ Q Aziz
}

See end of article for authors' affiliations

.....................

Correspondence to: Dr Lloyd J Gregory, GI Sciences, Clinical Sciences Building, Hope Hospital, Stott Lane, Salford, M6 8HD, UK; lloyd.gregory@ man.ac.uk

Accepted for publication 17 June 2003

\begin{abstract}
Background: While cortical processing of visceral sensation has been described, the role that cognitive factors play in modulating this processing remains unclear.

Aim: To investigate how selective and divided attention modulate the cerebral processing of oesophageal sensation.

Methods: In seven healthy volunteers (six males, mean age 33 years; ranging from 24 to 41 years old) from the general community, phasic visual and oesophageal (non-painful balloon distension) stimuli were presented simultaneously. During the selective attention task, subjects were instructed to press a button either to a change in frequency of oesophageal or visual stimuli. During a divided attention task, subjects received simultaneous visual and oesophageal stimuli and were instructed to press a button in response to a change in frequency of both stimuli.

Results: Selectively focussing attention on oesophageal stimuli activated the visceral sensory and cognitive neural networks (primary and secondary sensory cortices and anterior cingulate cortex respectively) while selective attention to visual stimuli primarily activated the visual cortex. When attention was divided between the two sensory modalities, more brain regions in the sensory and cognitive domains were utilised to process oesophageal stimuli in comparison to those employed to process visual stimuli $(p=0.003$ ). Conclusion: Selective and divided attention to visceral stimuli recruits more neural resources in both the sensory and cognitive domains than attention to visual stimuli. We provide neurobiological evidence that demonstrates the biological importance placed on visceral sensations and demonstrate the influence of cognitive factors such as attention on the cerebral processing of visceral sensation.
\end{abstract}

G astrointestinal (GI) pain is commonly observed in humans from time to time, usually due to dietary indiscretion, inflammation, or infection of the gastrointestinal tract. However, there are occasions where the exact cause of GI pain does not have an organic basis. Such conditions are collectively termed functional gastrointestinal disorders (FGID) and are often characterised by visceral hypersensitivity. The aetiology of visceral hypersensitivity in FGID such as irritable bowel syndrome (IBS) and noncardiac chest pain (NCCP) has been postulated to result from one, or a combination of the following: (i) sensitisation of gut afferent nerves, (ii) sensitisation of spinal cord afferents, or (iii) aberrant brain processing such that a non-noxious sensation is misinterpreted as noxious due to emotional or cognitive biasing.

Cognitive influences, such as heightened attention (hypervigilance) to the perception of visceral sensation are viewed as potential contributors to the pathogenesis of FGID..$^{1-4}$ In IBS, for example, a number of findings favour a psychological rather than a biological basis for increased pain sensitivity. First, IBS patients often rate even sham distensions as painful. ${ }^{5}$ Second, manipulation of IBS patients' attention and changes in arousal level produced by stress and relaxation alter the perceived intensity of distension related sensations. ${ }^{5-8}$ Thirdly, somatisation, the tendency to notice and then interpret many bodily sensations as symptoms of disease without any apparent physical cause, is common in FGID patients $^{19}$ and correlates with pain thresholds. ${ }^{10}$ Finally, it has been suggested that FGID patients are hypervigilant to GI sensation. ${ }^{11}$
Studies using functional brain imaging techniques have now begun to provide insight into the role that cognitive and emotional factors play in modulating the brain processing of somatic sensation. ${ }^{12-15}$ These studies highlight the importance of the neural network integrating cognitive and sensory information. Similar functional brain imaging techniques have also been used to identify brain areas that process human visceral sensation. ${ }^{16-23}$ These studies show that cortical processing of oesophageal sensation involves initial processing in the primary and secondary somatosensory cortices for sensory discrimination, with subsequent involvement of the anterior cingulate and prefrontal cortices for affect and cognition respectively. This indicates that it is possible not only to localise the origin of gut sensation but also to assign cognitive and emotional valence to it.

Cognitive neuroscience research suggests that factors such as attention are also known to play an important role in the perception of sensory input ${ }^{24-29}$ with numerous attentional mechanisms processing diverse sensory inputs. Examples of such mechanisms are selective attention in which attention is focussed on one stimulus when two or more concurrent stimuli are presented, and divided attention, when similar attention is given to multiple stimuli, when presented

\footnotetext{
Abbreviations: ACC, anterior cingulate cortex; $B O L D$, blood oxygenation level dependence; CNS, central nervous system; FGID, functional gastrointestinal disorder; $F M R I$, functional magnetic resonance imaging; GBAM, generic brain activation map; IBS, irritable bowel syndrome; NCCP, non-cardiac chest pain
} 
together. At present, no information is available on the neural networks involved in processing visceral sensation in the presence of situations requiring selective or divided attention.

We therefore examined the neural networks activated when healthy subjects selectively attended to one stimulus while ignoring the other and also when they divided attention between two competing stimuli using innocuous visual and oesophageal stimulation as the two stimuli. We have hypothesised that sensory and cognitive neuronal networks will be activated to a greater extent when attention is focussed on the biologically more important stimulus. We employed a visceral and visual stimulus for two reasons: Firstly, to compare the brain processing of two sensory modalities, stimuli that generated very different patterns of sensory brain activation were required. Secondly, an obvious candidate as an alternative sensory modality would be the auditory system. However, the rapid switching of magnetic field gradients during functional magnetic resonance imaging (fMRI) scanning generates background noise that could potentially interfere with discrimination between auditory background and target stimuli. Therefore, auditory stimuli were ruled out.

\section{MATERIALS AND METHODS \\ Subjects}

Seven healthy right handed volunteers (six males with a mean age 33 years) were recruited from personnel affiliated with the Department of Gastrointestinal Sciences, University of Manchester. All subjects gave informed, written consent prior to commencement of the study. Approval for the study was obtained from the local research ethics committee.

\section{Stimulation procedures}

\section{Oesophageal stimulation}

A $2 \mathrm{~cm}$ long silicon balloon was attached $15 \mathrm{~mm}$ from the tip of a $4 \mathrm{~mm}$ diameter multilumen polyvinyl manometry catheter (Wilson Cook, Letchworth, Herts, UK). The balloon was positioned in the distal oesophagus either $35 \mathrm{~cm}$ from the nostrils or $30 \mathrm{~cm}$ from the incisors, according to subject preference for the route of intubation. The balloon was repeatedly inflated with air using a purpose built, magnetic resonance compatible pump (Medical Physics Department, Hope Hospital, Salford, UK). The flow of air produced by the inflation pump was $12 \mathrm{l} / \mathrm{min}$.

In each subject, the balloon inflation pressure was increased in steps of 1 psi until a clearly perceptible but non-painful sensation was perceived. The background stimulus consisted of a series of non-painful, phasic balloon distensions to the oesophagus at six second intervals. The target stimulus consisted of two rapid phasic balloon distensions (at the same intensity as for the single distension); subjects were asked to confirm that the double distension remained non-painful. When subjects perceived the target stimulus, they responded by pressing a button which logged their reaction time to the target stimulus. The reaction time was measured as the time taken from the onset of the target stimulus to the time when the subject pressed the button. Following each experiment, subjects were asked whether the level of sensation had increased, decreased, or remained constant throughout.

\section{Visual stimulation}

Visual stimulation was delivered via a screen placed at the bottom of the scanning table onto which the stimuli were back projected. The background stimulus comprised a ring of 12 empty circles on a black background that filled sequentially with the colour red in a clockwise direction at a rate of one every six seconds. The target stimulus comprised a failure

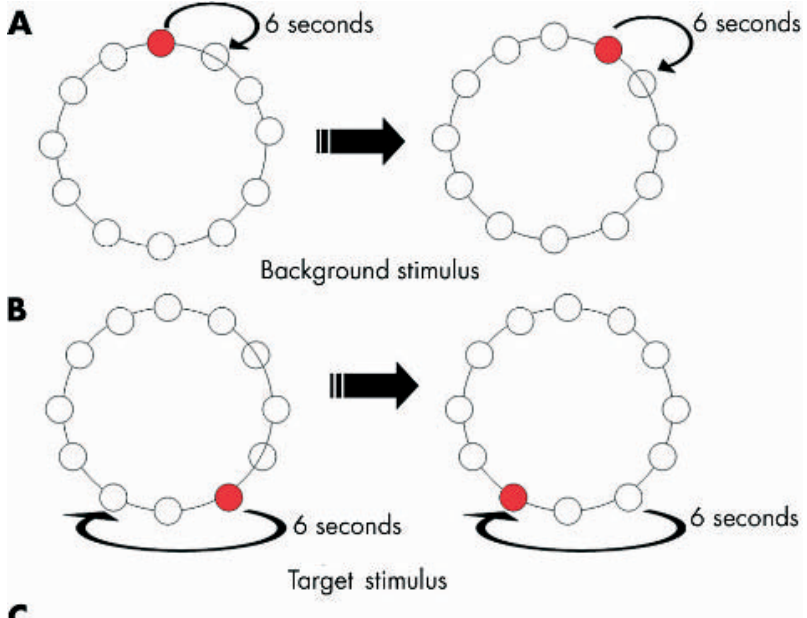

C

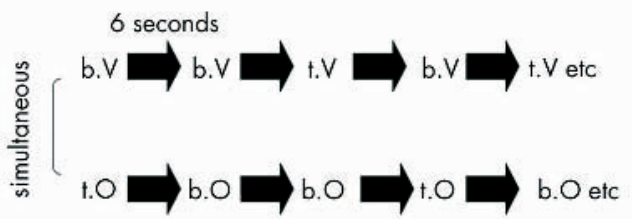

Figure 1 Schematic representation of the visual stimulus during background visual stimulation (A) and during target visual stimulation (B). During background visual stimulation, circles fill with colour in a clockwise direction at a rate of one every six seconds. As the next circle in the sequence is filled with colour, the previous circle empties. During target visual stimulation, there is a failure of a circle to fill with colour and the next circle following the empty circle fills with colour. When subjects detect the target visual stimulus, they indicate by pressing a button on a game pad. (C) Simplified schematic of protocol for selective and divided attention experiments. Note: The order of visual and oesophageal background and target stimuli are counterbalanced across all subjects for both selective and divided attention tasks. An interstimulus of six seconds occurs between each visual and oesophageal stimulus.

of one of the circles to fill with colour (figures IA and B). When subjects perceived the target stimulus-that is, a filled circle following an unfilled circle, they pressed the button which again recorded their reaction time to the target stimulus.

\section{Experimental protocols}

First, the catheter was inserted into the oesophagus and the balloon inflation pressure was adjusted so that the subjects received clearly perceptible, but non-painful oesophageal stimuli. They were then required to practice the oesophageal and visual tasks until they could discriminate the target from the background oesophageal and visual stimuli. Once this was established, they were placed in the magnetic resonance (MR) scanner. The order of presentation of the tasks was counterbalanced across all subjects and there was an interval of $5 \mathrm{~min}$ between the tasks to minimise habituation effects.

\section{Selective attention task}

The task comprised simultaneous presentation of visual and oesophageal stimuli and consisted of two conditions: (1) In the visual condition, the subjects were asked to attend selectively to the visual stimuli (and thus ignore the oesophageal stimuli) and press the button on the pad when they detected the visual target stimulus. (2) In the 
oesophageal condition, subjects were asked to attend selectively to the oesophageal target stimulus (and ignore the visual stimulus) and press the button on the pad when they detected the oesophageal target stimuli. The target visual and the target oesophageal stimuli were timed so that they would not occur at the same time.

Instructions regarding the modality the subjects were to attend to were presented on the screen for a period of $10 \mathrm{~s}$. Following that, the screen remained blank for a further $20 \mathrm{~s}$, before a period of $90 \mathrm{~s}$ of simultaneous background visceral and visual stimuli with intermittent target stimuli. The visual and oesophageal target stimuli were timed so that they would not occur at the same time. This process was repeated on four occasions each for both the visual and the oesophageal condition so that in each $90 \mathrm{~s}$ period there were eight visual or eight oesophageal targets. The order of presentation of the visual and oesophageal stimuli was counterbalanced between the subjects. The total duration of this experiment was 16 min. Reaction times, and number of correct and incorrect responses, were recorded.

\section{Divided attention task}

In this task, the background and target stimuli for both sensory modalities were the same as those in the selective attention experiment, presented in a different order. However, during this task, background visual and oesophageal stimuli were presented simultaneously, as in the selective attention experiment but subjects were instructed to pay attention to both sensory modality stimuli and indicate whenever they perceived the visual or oesophageal target stimuli. The visual and oesophageal target stimuli were timed so that they would not occur at the same time.

As in the selective attention task, the order of presentation of stimuli was counterbalanced across all subjects; the scan duration for this condition was $8 \mathrm{~min}$. Reaction time and the number of correct and incorrect responses were recorded.

For both the selective and divided attention experiments, the presentation of the oesophageal and visual stimuli were time locked, in so much as the stimulus onset for both oesophageal and visual background and target stimulus occurred every six seconds (for a simplified schematic representation of both experimental protocols, see figure IC).

\section{Image Acquisition}

Gradient echo echoplanar imaging (EPI) data were acquired on a GE Signa 1.5 T system (General Electric, Milwaukee WI, USA) at the Maudsley Hospital, London, UK. Daily quality assurance was carried out to ensure high signal to ghost ratio, consistent signal to noise ratio, and excellent temporal stability using an automated quality control procedure. A quadrature birdcage headcoil was used for radio frequency (RF) transmission and reception. $100 \mathrm{~T}_{2}{ }^{*}$-weighted images depicting blood oxygenation level dependence (BOLD) contrast were acquired during the experiment at each of 16 near-axial non-contiguous $7 \mathrm{~mm}$ thick planes parallel to the intercommissural (AC-PC) line: TE $40 \mathrm{msec}$, TR $3 \mathrm{~s}$, interslice gap $0.7 \mathrm{~mm}$. The slices had an in-plane resolution of $3.1 \mathrm{~mm}$. Head movement was limited by foam padding within the head coil and a restraining band across the forehead. During the same session, a 43 slice, high resolution gradient echo EPI image of the whole brain was acquired in the AC-PC plane with a $\mathrm{TE}=40 \mathrm{~ms} \mathrm{TR}=3000 \mathrm{~ms}$. The in-plane resolution was $3.75 \mathrm{~mm}$ and the slice thickness was $3 \mathrm{~mm}$ with a $0.3 \mathrm{~mm}$ interslice gap. This higher resolution image allowed subsequent superimposition of areas of activation from the lower resolution BOLD images. Image artefacts caused by subject motion during the course of the functional study were minimised using locally developed image realignment software. $^{30}$
The design of the experimental tasks was carefully constructed to take into account the long haemodynamic response function measured in BOLD based fMRI (typically $6 \mathrm{~s}$ from stimulus presentation). Therefore, the subtle (ms) temporal offset between the two phasic distensions would not be discriminated in the convolved fMRI response.

\section{fMRI data analysis}

\section{Movement estimation and correction}

Small amounts of subject motion during the experiment were corrected by first computing an average volume over all time points and using this as a base or target volume for realignment. Using the Fletcher-Davidon-Powell algorithm, the total absolute difference between each match volume and the base volume was minimised, and match volumes were realigned by tricubic spline interpolation. The $\mathrm{T}_{2}{ }^{*}$-weighted signal intensity time series at each voxel of the realigned images were regressed on the concomitant and lagged time series of estimated positional displacements at each voxel. ${ }^{31}$ The residual time series resulting from the last stage of this procedure are uncorrelated with estimated rigid body motion in $3 \mathrm{D}$.

\section{Modelling}

A modification of the method of Friston et $a^{32}$ has been developed in which BOLD responses are modelled as the weighted sum of the input function convolved with two Poisson functions. A goodness of fit statistic was computed as the ratio of the modelled and residual sums of squares (SSQratio). Under randomisation testing the SSQratio can be used to replace an F test. The SSQratio does not require knowledge of the degrees of freedom in the model or the residuals. Voxel-wise inference was carried out non-parametrically, and individual maps were identified by spatiotemporal randomisation testing. ${ }^{33}$ At the group level, individual statistic maps were transformed into standard stereotactic space using a two stage procedure; smoothed using a Gaussian filter FWHM $7.2 \mathrm{~mm}$, and median activation images constructed as described by Brammer et al. ${ }^{34}$

\section{Comparing conditions}

To identify those voxels that demonstrate significant difference in standardised power of response between various conditions, the observed difference in the median SSQratio between the two experimental conditions was computed at each voxel. This process was repeated 64 times at each voxel, and the results were pooled over voxels to generate a null distribution for the difference in median SSQratio. For a two tailed test of size $p<0.003$, the critical values were the $100 * \mathrm{p} / 2$ th and $100 *(1-\mathrm{p} / 2)$ th percentiles of the randomisation distribution. Note this probability threshold was used to test for a differential power of response between experiments only at those voxels that were significantly activated in one or both the generic brain activation maps (GBAMs) separately computed for each experiment. ${ }^{20}{ }^{35}$ Therefore, from the selective attention experiment, we compared selective attention to visual targets $v$ selective attention to oesophageal targets (visual $v$ oesophageal). From the divided attention experiment we compared attention to visual targets $v$ attention to oesophageal targets (visual and oesophageal).

\section{Behavioural data analysis}

The median reaction times were calculated for each subject in both selective and divided attention experiments. Comparisons between reaction times to visual and oesophageal target stimuli in the selective and divided attention tasks were performed using a two tailed paired t test. 


\section{RESULTS}

All subjects tolerated the experiments well, no change in character or severity of oesophageal sensation occurred during the experiments.

\section{Selective attention task}

\section{Behavioural responses}

Subjects took longer to react to the oesophageal target stimuli (1200ms) than to the visual target stimuli $(480 \mathrm{~ms}$; $\mathrm{t}=-17.742, \mathrm{df}=6, \mathrm{p}<0.0001)$. However, their accuracy in terms of number of errors made was similar for the two sensory modalities $(p=0.199)$. These data are summarised in table 1 .

\section{Brain activation (visual $v$ oesophageal comparison) Visual condition}

When subjects were asked to focus their attention on the visual targets while ignoring the oesophageal, target stimuli activation was observed mainly in the visual cortex and superior parietal lobule (table 2).

\section{Oesophageal condition}

When subjects were asked to focus their attention on the oesophageal target stimuli while ignoring the visual target stimuli patterns of cerebral activation were observed in the following brain regions: mid-anterior cingulate cortex (BA24), prefrontal cortex, posterior parietal (primary and secondary somatosensory cortices), insular, thalamus, hippocampus, amygdala, and cerebellum.

The significant differences $(p=0.003)$ between selective attention to visual and selective attention to oesophageal targets are shown in table 2 and figure $2 \mathrm{~A}$.

\section{Divided attention task}

\section{Behavioural responses}

The reaction time to visual target stimuli during the divided attention task was 510 (110) ms. Reaction time to oesophageal target stimuli during the divided attention task was 1220 (70) ms During this condition, subjects took significantly longer to respond to the oesophageal target stimuli compared to the visual target stimuli ( $1220 \mathrm{~ms} v 510 \mathrm{~ms}$ respectively; $\mathrm{t}=-14.83, \mathrm{df}=6, \mathrm{p}<0.01)$. There were no differences between the two tasks for the number of errors made $(\mathrm{p}=0.08)$. These data are summarised in table 3 .

\section{Brain activation}

\section{Visual and oesophageal condition}

When subjects divided their attention between competing visual and oesophageal targets, there was an increase in neural resources allocated towards processing the oesopha-

Table 1 Correct number of responses (out of a total of 32) and false positives for each subject are shown during either selective attention to visual or oesophageal target stimuli

\begin{tabular}{lllll}
\hline Subject & $\begin{array}{l}\text { Number of } \\
\text { correct visual } \\
\text { responses out } \\
\text { of } 32\end{array}$ & $\begin{array}{l}\text { Number of } \\
\text { visual false } \\
\text { positive } \\
\text { responses }\end{array}$ & $\begin{array}{l}\text { Number of } \\
\text { correct visceral } \\
\text { responses out } \\
\text { of } \mathbf{3 2}\end{array}$ & $\begin{array}{l}\text { Number of } \\
\text { visceral false } \\
\text { positive } \\
\text { responses }\end{array}$ \\
\hline 1 & 32 & 0 & 32 & 0 \\
2 & 32 & 2 & 32 & 2 \\
3 & 32 & 2 & 31 & 0 \\
4 & 32 & 0 & 32 & 1 \\
5 & 32 & 0 & 32 & 0 \\
6 & 32 & 0 & 32 & 0 \\
7 & 31 & 0 & 29 & 0 \\
\hline
\end{tabular}

Table 2 Comparison of brain regions activated during selective attention to oesophageal stimuli $v$ selective attention to visual stimuli

\begin{tabular}{|c|c|c|c|c|c|c|c|}
\hline Brain region & Side & $\mathbf{x}$ & $y$ & z & BA & Size & Condition \\
\hline $\begin{array}{l}\text { Superior frontal } \\
\text { gyrus }\end{array}$ & $R$ & 17 & 20 & 48 & 8 & 51 & oesophageal \\
\hline $\begin{array}{l}\text { Superior frontal } \\
\text { gyrus }\end{array}$ & $\mathrm{R}$ & 17 & 33 & 42 & 8 & 39 & oesophageal \\
\hline Globus pallidus & $\mathrm{R}$ & 15 & 4 & 4 & - & 47 & oesophageal \\
\hline Cerebellum & L & -7 & -67 & -24 & - & 46 & oesophageal \\
\hline Cerebellum & $\mathrm{R}$ & 11 & -67 & -29 & - & 30 & oesophageal \\
\hline $\begin{array}{l}\text { Mid-anterior } \\
\text { cingulate gyrus }\end{array}$ & $\ddot{L}$ & -17 & -4 & 42 & 24 & 38 & oesophageal \\
\hline Thalamus & L & -11 & -4 & 9 & - & 38 & oesophageal \\
\hline $\begin{array}{l}\text { Dorsolateral } \\
\text { prefrontal cortex }\end{array}$ & $\mathrm{R}$ & 11 & 39 & 37 & 9 & 35 & oesophageal \\
\hline $\begin{array}{l}\text { Secondary sensory } \\
\text { cortex }\end{array}$ & $\mathrm{L}$ & -53 & -4 & 15 & 4 & 27 & oesophageal \\
\hline $\begin{array}{l}\text { Supplementary } \\
\text { motor area }\end{array}$ & $\mathrm{L}$ & -53 & 0 & 9 & 6 & 23 & oesophageal \\
\hline $\begin{array}{l}\text { Supplementary } \\
\text { motor area }\end{array}$ & $R$ & 7 & 4 & 53 & 6 & 12 & oesophageal \\
\hline $\begin{array}{l}\text { Motor area } 1 \\
\quad \text { (lower extremity) }\end{array}$ & $\mathrm{R}$ & 21 & -26 & 42 & 4 & 21 & oesophageal \\
\hline $\begin{array}{l}\text { Motor area } 1 \\
\text { (lower extremity) }\end{array}$ & L & -32 & -10 & 37 & 4 & 12 & oesophageal \\
\hline $\begin{array}{l}\text { Primary sensory } \\
\text { cortex }\end{array}$ & $\mathrm{R}$ & 40 & -26 & 48 & 1 & 21 & oesophageal \\
\hline Putamen & $\mathrm{R}$ & 17 & 7 & -2 & - & 20 & oesophageal \\
\hline $\begin{array}{l}\text { Superior temporal } \\
\text { gyrus }\end{array}$ & L & -53 & 0 & 4 & 22 & 20 & oesophageal \\
\hline $\begin{array}{l}\text { Posterior cingulate } \\
\text { gyrus }\end{array}$ & $\mathrm{R}$ & 11 & -26 & 37 & 31 & 17 & oesophageal \\
\hline Precuneus & $\mathrm{R}$ & 7 & -67 & 31 & 7 & 17 & oesophageal \\
\hline Hippocampus & $\mathrm{L}$ & -21 & -37 & 4 & - & 16 & oesophageal \\
\hline Primary visual cortex & $\mathrm{R}$ & 15 & -67 & 26 & 18 & 14 & oesophageal \\
\hline Cuneus & $\mathrm{R}$ & 11 & -69 & 9 & 31 & 14 & oesophageal \\
\hline Insula & L & -32 & 23 & -2 & - & 13 & oesophageal \\
\hline Corpus striatum & $\mathrm{L}$ & -7 & 4 & 20 & - & 11 & oesophageal \\
\hline Primary visual cortex & $\mathrm{L}$ & -17 & -52 & -2 & 19 & 10 & visual \\
\hline $\begin{array}{l}\text { Superior parietal } \\
\text { lobule }\end{array}$ & L & -4 & -30 & 48 & 5 & 9 & visual \\
\hline
\end{tabular}

Side: left $(L)$ or right $(R)$; stereotaxic coordinates $(x, y, z)$; BA, Brodmann area; number of voxels (size) activated.

geal target stimuli compared to those recruited to process the visual target stimuli $(\mathrm{p}=0.003$; see figure $2 \mathrm{~B})$.

When subjects responded to the visual target stimuli during this condition, activation was observed in the visual cortex, middle temporal gyrus, inferior parietal lobe (BA 40), precuneus, amygdala, and primary somatosensory cortex. Conversely, when subjects responded to the oesophageal target stimulus activation was observed in the orbitofrontal cortex, insular cortex, premotor cortex adjacent to dorsolateral prefrontal cortex, anterior cingulate cortex, posterior cingulate cortex, putamen, cerebellar vermis, fusiform gyrus (BA 20), hippocampus, inferior frontal gyrus (BA 45), and caudate nucleus.

The number of voxels, hemisphere, Taleraich coordinates and brain regions activated during this task are shown in table 4.

\section{DISCUSSION}

Our study demonstrates that more brain regions are recruited to process oesophageal sensation both when subjects are required to selectively focus attention on one sensory modality while ignoring the other and also when there is competing sensory input from the two modalities and attention is divided between these. As well as consciously "filtering out" the simultaneous input from the other sensory modality during the selective attention experiment, our results demonstrate that the associated brain regions of the ignored stimulus are not activated during this task. Similarly, 


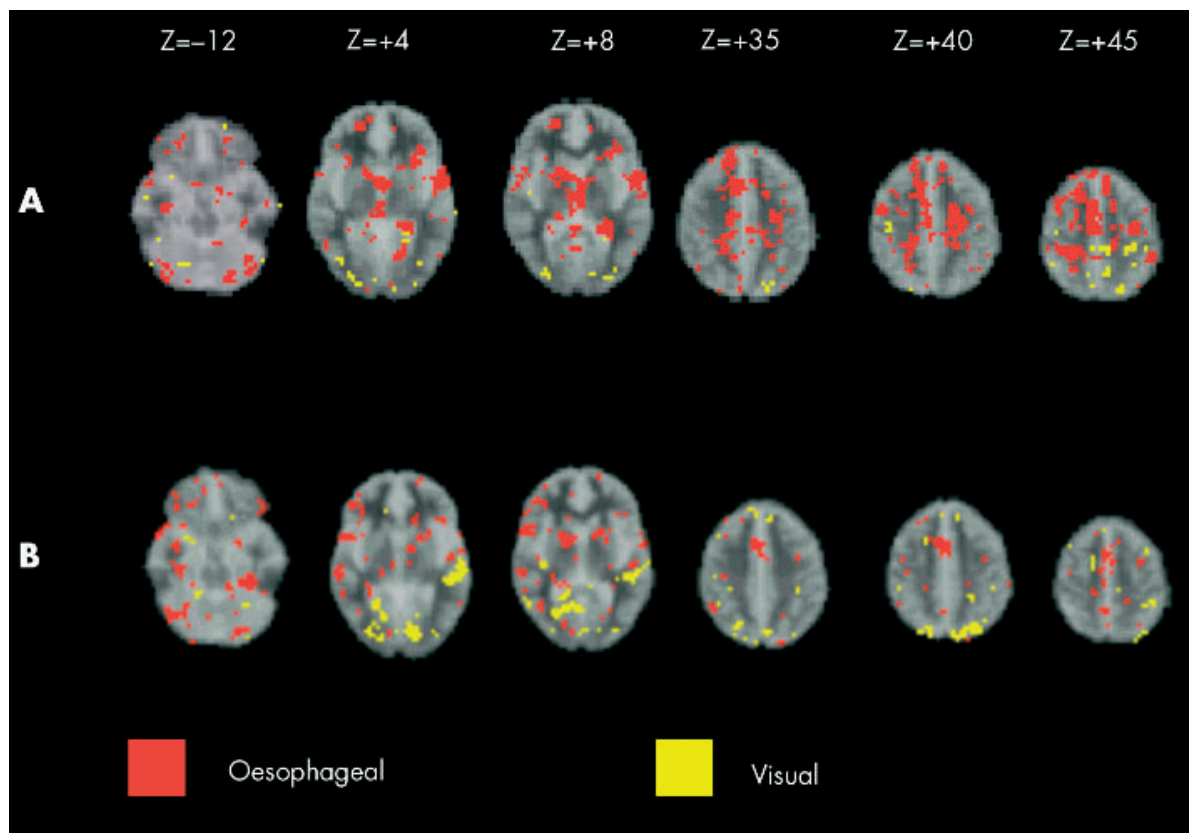

Figure 2 (A) Comparison of brain activation between selective attention to visual (yellow) and selective attention to oesophageal (red) stimuli. Images run inferior to superior (left to right). (B) Comparison of brain activation between divided attention to visual (yellow) and divided attention to oesophageal stimuli (red). Images run inferior to superior (top left to bottom right). Stereotactic ( $z$ ) coordinate is shown across the top of the figure. Note: the comparisons of oesophageal $v$ visual targets in both selective and divided attention experiments were generated from the product of the target stimuli of sensory modality 1 (for example, visual) subtracted from a standardised rest condition (that is generated from interstimulus intervals) being compared to the product of target stimuli of sensory modality 2 (for example, visceral) subtracted from a standardised rest condition.

our results reveal that we are able to divide our attention between the different sensory modalities with corresponding activation of stimulus appropriate neural domains.

In the selective attention task, we found that when attention was focussed on oesophageal stimuli there was activation of the "sensory" brain regions - that is, the insular cortex, primary and secondary sensory cortices, and "cognitive" regions, such as the anterior cingulate and prefrontal cortices. In contrast, when attention was focussed on visual stimuli cerebral activation was observed in regions primarily concerned with the sensory processing of visual information, with little or no involvement of cognitive regions.

The precise reason for this difference in the cognitive processing of oesophageal and visual sensory information in the selective attention task is not clear. However, it is known that anterior cingulate cortex (ACC) activation depends strongly on "the intrusive nature of a stimulus to capture awareness". ${ }^{13} 36$ It is possible therefore that increased activation in the ACC during attention to the oesophageal stimuli could be due to the novelty of the visceral sensation, normally processed at a subliminal level, now being processed consciously. Here the subject recognises the novelty and potentially threatening nature of the oesophageal stimulus and allocates more cognitive resource towards processing it. In contrast, the visual target stimulus used in our study had less novelty or salience associated with it suggesting that

Table 3 Correct number of responses (out of a total of 32) and false positives for each subject are shown during divided attention to visual and oesophageal target stimuli

\begin{tabular}{lllll}
\hline Subject & $\begin{array}{l}\text { Number of } \\
\text { correct visual } \\
\text { responses out } \\
\text { of } 32\end{array}$ & $\begin{array}{l}\text { Number of } \\
\text { visual false } \\
\text { positive } \\
\text { responses }\end{array}$ & $\begin{array}{l}\text { Number of } \\
\text { correct visceral visceral false } \\
\text { responses out } \\
\text { of } 32\end{array}$ & $\begin{array}{l}\text { Number of } \\
\text { positive } \\
\text { responses }\end{array}$ \\
\hline 1 & 32 & 0 & 30 & 0 \\
2 & 32 & 0 & 32 & 0 \\
3 & 32 & 0 & 31 & 0 \\
4 & 32 & 0 & 30 & 0 \\
5 & 32 & 0 & 25 & 0 \\
6 & 32 & 2 & 31 & 0 \\
7 & 32 & 0 & 32 & 0 \\
\hline
\end{tabular}

subjects habituated to the stimulus more readily. In fact studies have demonstrated that when subjects are asked to remain vigilant to a particular repetitive stimulus, there is a "dampening" of activation in the ACC due to habituation. $^{13}{ }^{36-39}$

It is notable that during the selective attention task, subjects were successful in ignoring sensory information related to the modality that was not being attended to and this was reflected in the patterns of activation observed. For

Table 4 Comparison of brain activation of visual stimuli $v$ oesophageal stimuli during the divided attention task

\begin{tabular}{|c|c|c|c|c|c|c|c|}
\hline Cerebral region & Side & $\mathbf{x}$ & y & $\mathbf{z}$ & BA & Size & Condition \\
\hline $\begin{array}{l}\text { Posterior cingulate } \\
\text { gyrus }\end{array}$ & $\mathrm{R}$ & 7 & -63 & & 31 & 44 & visual \\
\hline Primary visual cortex & $\mathrm{R}$ & 15 & -86 & -7 & 18 & 27 & visual \\
\hline Parietal precuneus & $\mathrm{L}$ & -7 & -73 & 42 & 7 & 20 & visual \\
\hline Middle temporal gyrus & $\mathrm{L}$ & -47 & -33 & -2 & 21 & 20 & visual \\
\hline Anterior cingulate gyrus & $s \mathrm{R}$ & 7 & 7 & 42 & 32 & 16 & oesophageal \\
\hline Fusiform gyrus & L & -32 & -33 & -13 & 18 & 16 & oesophageal \\
\hline Cerebellum & $\mathrm{R}$ & 25 & -56 & -18 & & 15 & oesophageal \\
\hline Fusiform gyrus & $\mathrm{L}$ & -32 & -33 & -18 & 18 & 14 & oesophageal \\
\hline $\begin{array}{l}\text { Superior temporal } \\
\text { gyrus }\end{array}$ & $\mathrm{R}$ & 40 & 10 & -13 & 47 & 14 & oesophageal \\
\hline $\begin{array}{l}\text { Anterior-mid cingulate } \\
\text { gyrus }\end{array}$ & $\mathrm{R}$ & 7 & 10 & 37 & 24 & 13 & oesophageal \\
\hline $\begin{array}{l}\text { Posterior cingulate } \\
\text { gyrus }\end{array}$ & $\mathrm{R}$ & 28 & -63 & 26 & 31 & 12 & visual \\
\hline Putamen & $\mathrm{R}$ & 17 & 0 & 4 & & 12 & oesophageal \\
\hline Primary visual cortex & $\mathrm{R}$ & 17 & -50 & 4 & 18 & 11 & visual \\
\hline Corpus striatum & $\mathrm{R}$ & 15 & 0 & 15 & & 11 & oesophageal \\
\hline Primary visual cortex & $\mathrm{L}$ & -11 & -73 & -7 & 18 & 11 & visual \\
\hline Putamen & $\mathrm{R}$ & 15 & 0 & 9 & & 11 & oesophageal \\
\hline $\begin{array}{l}\text { Posterior cingulate } \\
\text { gyrus }\end{array}$ & $\mathrm{L}$ & -4 & -43 & 26 & 31 & 11 & oesophageal \\
\hline Primary visual cortex & $\mathrm{R}$ & 28 & -80 & -2 & 18 & 11 & visual \\
\hline Middle temporal gyrus & $\mathrm{L}$ & -53 & -20 & -7 & 21 & 10 & visual \\
\hline Medial frontal lobe & $\mathrm{R}$ & 11 & 17 & 31 & & 10 & oesophageal \\
\hline $\begin{array}{l}\text { Primary visual cortex } \\
\qquad 1\end{array}$ & $\mathrm{R}$ & 17 & -86 & -13 & 17 & 10 & visual \\
\hline Insular cortex & $\mathrm{R}$ & 47 & 7 & 4 & & 10 & oesophageal \\
\hline Primary visual cortex & $\mathrm{R}$ & 21 & -52 & -2 & 19 & 10 & visual \\
\hline Hippocampus & $\mathrm{L}$ & -40 & -39 & -7 & & 9 & oesophageal \\
\hline Premotor cortex & $\mathrm{R}$ & 43 & -4 & 26 & 6 & 9 & oesophageal \\
\hline
\end{tabular}

Side: left (L) or right $(R)$; stereotaxic coordinates $(x, y, z)$; BA, Brodmann area; number of voxels (size) are shown. 
example, during attention to visual target stimuli, activation was significantly attenuated in sensory regions normally associated with processing oesophageal sensation and vice versa. Our findings demonstrate in part, the neural correlates for when we ignore sensory input that is not immediately relevant to us, to focus on that which is.

In the divided attention task, when attention was diverted towards the visual target stimuli, we observed activation in the visual cortex together with activation in sensory and brain regions that are normally associated with processing oesophageal sensation. Similarly, when attention was diverted towards the oesophageal stimulus we saw activation in the sensory and cognitive regions associated with processing oesophageal sensation along with some activation of regions normally associated with processing visual sensation. The data demonstrate the human ability to divert neural resources to processing more than one stimulus. However, the activation in more of the sensory and cognitive domains in response to attending to oesophageal stimuli may reflect a processing prioritisation for sensations arising from the viscera, even when there is competition for neural resources from other sensory modalities, because sensations arising from the viscera are often important indicators of tissue damage, inflammation, or potential harm to an organism. Activation of the orbitofrontal cortex which is associated with negative, aversive events ${ }^{40}$ and the ACC normally activated when sensory experience captures awareness during attention to oesophageal targets, further strengthens our argument pertaining to the relevance of visceral sensation.

Other studies have explored the functional significance of the sensory cognitive brain regions involved in processing input from different sensory modalities. A Recent study by Peyron et al investigated the neural correlates of sensory and attentional networks for somatic pain using positron emission tomography (PET). ${ }^{13}$ Their results illustrate that insular and secondary somatosensory cortices mediate the sensory discriminative component of pain while the thalamus, prefrontal, posterior parietal, and in particular the anterior cingulate cortices mediate the attentional aspects of pain. Similarly in our study, the patterns of activation observed in the insular and secondary somatosensory cortices, thalamus, prefrontal cortex, and in particular the ACC are more likely to be related to attentional factors as we did not use a painful oesophageal stimulus. Activation of the insular cortex has been reported previously by our laboratory in response to non-painful visceral sensation along with activation of the primary and secondary somatosensory cortices. ${ }^{18} 2041$ Although there is no direct evidence to suggest that the insular cortex has some role to play in attention processing, it does connect to brain regions that communicate with the ACC and therefore may form part of the neural circuitry concerned with attentional processing.

Activation in the cerebellum was observed consistently across all our tasks. Previously, the cerebellum has been shown to play an important role in sensorimotor integration..$^{42}$ In a recent study from our laboratory, we have shown activation of the cerebellum in response to non-painful visceral sensations. ${ }^{20}$ There is also a growing body of evidence to suggest that the cerebellum is involved in cognitive processing. ${ }^{43-46}$ More recently, a study by Allen et al suggested that the cerebellum may have an important role to play in processing attention based information. ${ }^{47}$ Our findings from the present study suggest that the cerebellum may be involved in mediating selective attention to specific sensory input.

Our neuroimaging results suggest that differences exist between the cognitive demands placed on the sensory stimuli in the selective and divided attention experiments. We propose that in the selective attention experiments, more importance is placed on the oesophageal stimuli compared to the visual stimuli resulting in greater activation in cognitive and visceral sensory brain regions with little activation in cognitive and visual sensory brain regions. However, during the divided attention experiments, where attention is distributed between the visual and oesophageal stimuli there appears to be greater activation in visual sensory brain regions. This may be due to constantly switching back-andforth from visceral to visual stimuli resulting in resource limitation and less brain regions that can respond to the oesophageal targets because resources have to be divided between the visceral and visual targets. Further studies are required in order to explore this phenomenon fully.

The shorter reaction time to respond to the visual targets in comparison to oesophageal targets may well be due to differences in afferent neural pathways that transmit information from the two sensory regions to the central nervous system (CNS). There is almost a direct input from the eye to the visual cortex. Whereas information arising from the oesophagus will take longer due to slower transduction velocities of visceral afferents. ${ }^{48}$ Even though our data suggest that the oesophageal stimulus has more novelty and therefore we may expect the reaction time to be quicker to novel stimuli, the slower conduction velocity of sensory information arriving at the CNS would prevent this from happening.

Due to the inherent nature of selective and divided attention experiments (whereby two or more stimuli are presented simultaneously as background "non-targeted" stimuli) it would be difficult to interrogate the neural correlates of the non-targeted oesophageal and visual stimuli because cortical activation resulting from background oesophageal and background visual stimuli occur together.

The primary focus of this study was to establish a model in healthy volunteers in order to examine the influence of cognitive factors on the normal cerebral processing of visceral sensation, so that this model could later be used to compare how FGID patients respond to cognitive modulation. Although we have not studied FGID patients, one can speculate that differences in cerebral processing would be observed between FGID patients and healthy subjects, when exposed to selective and divided attention tasks. Our hypothesis is that FGID patients with hypervigilance to visceral sensation will find it more difficult to distract themselves from the visceral stimulus in the selective attention task or, equally find it more difficult to attend to the visual stimulus in the divided attention tasks, leading to even greater activation of visceral sensory and cognitive brain regions in comparison to healthy subjects. Our study provides the basis for this hypothesis to now be tested in an objective manner.

\section{CONCLUSION}

We have provided a model that demonstrates how attention towards an innocuous visceral sensation recruits more brain regions in the cognitive and sensory domains compared to when attention is directed towards an innocuous stimulus in another sensory modality. We believe that this phenomenon is most likely due to the novelty and greater salience of oesophageal sensation in comparison to visual stimulation. However, this is the first time that such neuroimaging experiments have been performed using non-painful visceral and visual sensory stimuli as sensory modalities. In order to establish what comparative level of salience would be required to direct attention away from the oesophageal stimulus and onto the visual stimulus will require further, in depth experimentation where the salience of the visual stimulus is systematically increased. 
Our preliminary experiments have laid the foundations for further studies that may be useful for exploring vigilance to visceral sensation in both organic and functional disorders of the GI tract.

\section{ACKNOWLEDGEMENTS}

QA is a Medical Research Council (MRC) Clinician Scientist. We would like to thank Anthony Hobson, GI physiologist and Research Fellow for technical support. We would like to acknowledge the assistance of $\mathrm{Mr}$ Christopher Andrew, Chief Technician, Neuroimaging Research Group for his technical advice. Finally, we would like to thank Professor Jeffrey Gray for his valuable discussions during manuscript preparation.

\section{Authors' affiliations}

L J Gregory, D G Thompson, Q Aziz, Section of GI Sciences, University of Manchester, Manchester, UK

L Yágüez, S C R Williams, S J Coen, V Ng, M J Brammer, Departments of Psychology, Neurology, and Biostatistics, Institute of Psychiatry, King's College London, University of London, UK

C Altmann, Department of Cognitive and Computational Psychophysics, Max Planck Institute for Biological Cybernetics, Tubingen, Germany

\section{REFERENCES}

1 Gwee KA, Leong YL, Graham C, et al. The role of psychological and biological factors in postinfective gut dysfunction. Gut 1999;44:400-6.

2 Hollerbach S, Fitzpatrick D, Shine G, et al. Cognitive evoked potentials to anticipated oesophageal stimulus in humans: quantitative assessment of the cognitive aspects of visceral perception. Neurogastroenterol Motil 1999;111:37-46.

3 Mayer EA, Gebhart G. Basic and clinical aspects of visceral hyperalgesia. Gastroenterology 1994; 107:271-93.

4 Ness T, Gebhart G. Visceral pain: a review of experimental studies. Pain 1990:41:167-234.

5 Silverman D, Munakata JA, Ennes $\mathrm{H}$, et al. Regional cerebral activity in normal and pathological perception of visceral pain. Gastroenterology 1997;112:64-72.

6 Accarino AM, Azpiroz F, Malagelada JR. Attention and distraction: effects on gut perception. Gastroenterology 1997;113:415-22.

7 Ford MJ, Camilleri M, Zinsmeister AR, et al. Psychosensory modulation of colonic sensation in the human transverse and sigmoid colon. Gastroenterology 1995;109:1772-80.

8 Prior A, Colgan SM, Whorwell PJ. Changes in rectal sensitivity after hypnotherapy in patients with irritable bowel syndrome. Gut 1990;31:896-8.

9 Heaton KW, O'Donnell $\amalg$, Braddon FE, et al. Symptoms of irritable bowel syndrome in a British urban community: consulters and nonconsulters. Gastroenterology 1992;102:1962-7.

10 Whitehead W, Palsson O. Is rectal pain sensitivity a biological marker for irritable bowel syndrome: psychological influences on perception. Gastroenterology 1997; 115:1263-71.

11 Mayer EA, Raybould H. Role of visceral afferent mechanisms in functional bowel disorders. Gastroenterology 1990;99:1688-1704.

12 Derbyshire SW, Vogt BA, Jones AK. Pain and stroop interference tasks activate separate processing modules in anterior cingulate cortex. Exp Brain Res 1998; 1 18:52-6.

13 Peyron R, Garcia-Larrea L, Gregoire MC, et al. Haemodynamic brain responses to acute pain in humans: sensory and attentional networks. Brain 1999; 122:1765-79.

14 Ploghaus A, Tracey I, Clare S, et al. Learning about pain: the neural substrate of the prediction error for aversive events. Proc Natl Acad Sci USA 2000;97:9281-6.

15 Petrovic $\mathbf{P}$, Petersson KM, Ghatan $\mathrm{PH}$, et al. Pain related cerebral activation is altered by a distracting cognitive task. Pain 2000;85:19-30.

16 Furlong PL, Aziz Q, Singh KD, et al. Cortical localization of magnetic fields evoked by oesophageal distension. Electrolencephalogr Clin Neurophysiol 1998; 108:234-43.

17 Hobday DI, Aziz Q, Thacker N, et al. A study of the cortical processing of ano-rectal sensation using functional MRI. Brain 2001;124:361-8.
18 Aziz $\mathbf{Q}$, Andersson JL, Valind $\mathrm{S}$, et al Identification of human brain loci processing oesophageal distension using positron emission tomography. Gastroenterology 1997;113:50-60.

19 Aziz Q, Thompson DG. Brain-gut axis in health and disease. Gastroenterology 1998;114:559-78.

20 Aziz Q, Thompson DG, Ng VWK, et al. Cortical processing of human somatic and visceral sensation. J Neurosci 2000;20:2657-63.

21 Schnitzler A, Volkmann J, Enck P, et al. Different cortical organization of visceral and somatic sensation in humans. Eur J Neurosci 1999:11:305-15.

22 Binkofski F, Schnitzler A, Enck P, et al. Somatic and limbic cortex activation in esophageal distention: a functional magnetic resonance imaging study. Ann Neurol 1998;44:811-15.

23 Mertz H, Morgan V, Tanner G, et al. Regional cerebral activation in irritable bowel syndrome and control subjects with painful and non-painful rectal distension. Gastroenterology 2000;1 18:842-8.

24 Keogh E, Hatton K, Ellery D. Avoidance versus focussed attention and the perception of pain: differential effects for men and women. Pain 2000:85:225-30.

25 Hadjistavropoulos HD, Hadjistavropoulos T, Quine A. Health anxiety moderates the effects of distraction versus attention to pain. Behav Res Ther 2000;38:425-38

26 Levine JD, Gordon NC, Smith R, et al. Post-operative pain: effect of extent of injury and attention. Brain Res 1982;234:500-4.

27 Miron D, Duncan GH, Bushnell MC. Effects of attention on the intensity and unpleasantness of thermal pain. Pain 1989;39:345-52

28 Bushnell MC, Duncan GH, Hofbauer RK, et al. Pain perception: is there a role for primary somatosensory cortex? Proc Natl Acad Sci USA 1999:96:7705-9.

29 Rode S, Salkovskis PM, Jack T. An experimental study of attention, labelling and memory in people suffering from chronic pain. Pain 2001;94:193-203.

30 Bullmore ET, Brammer MJ, Rabe-Hesketh S, et al. Methods for diagnosis and treatment of stimulus-correlated motion in generic brain activation studies using fMRI. Hum Brain Mapp 1999:7:38-48.

31 Friston KJ, Williams S, Howard R, et al. Movement-related effects in fMRI time-series. Magn Reson Med 1996;35:346-55.

32 Friston KJ, Fletcher P, Josephs O, et al. Event-related FMRI: characterizing differential responses. Neuroimage 1998:7:30-40.

33 Bullmore ET, Long C, Suckling J, et al. Coloured noise and computational inference in neurophysiological (fMRI) time series analysis: resampling methods in time and wavelet domains. Hum Brain Mapp 2001;12:61-78.

34 Brammer MJ, Bullmore ET, Simmons A, et al. Generic brain activation mapping in functional magnetic resonance imaging: a nonparametric approach. Magn Reson Imaging 1997;15:763-70.

35 Phillips ML, Young AW, Senior C, et al. A specific neural substrate for perceiving facial expressions of disgust. Nature 1997:389:495-8.

36 Posner Ml. Attention: the mechanisms of consciousness. Proc Natl Acad Sci USA 1994:91:7398-403.

37 Grafton ST, Woods RP, Tyszka M. Functional imaging of procedural motor learning: relating cerebral blood flow with individual subject performance. Hum Brain Mapp 1994;1:221-34.

38 Davis KD, Talylor SJ, Crawley AP, et al. Functional MRI of pain- and attentionrelated activations in the human cingulate cortex. J Neurophysiol 1997;77:3370-80

39 Bush G, Whalen PJ, Rosen BR, et al. The counting stroop: an interference task specialized for functional neuroimaging. Validation study with functional MRI. Hum Brain Mapp 1998;6:270-82.

40 Lotze $M$, Wietek B, Birbaumer N, et al. Cerebral activation during anal and rectal stimulation. Neuroimage 2001;14:1027-34.

41 Aziz Q, Rothwell JC, Hamdy S, et al. The topographic representation of esophageal motor function on the human cerebral cortex. Gastroenterology 1996;111:855-62.

42 Roland PE. Partition of the human cerebellum in sensory-motor activities, learning and cognition. Can J Neurol Sci 1993;20:S75-7.

43 Wallesch C-W, Horn A. Long-term effects of cerebellar pathology on cognitive functions. Brain Cogn 1990;14:19-25.

44 Grafman J, Litvan I, Massaquoi S, et al. Cognitive planning deficit in patients with cerebellar atrophy. Neurology 1992;42:1493-6.

45 Appollonio IM, Grafman J, Schwartz V, et al. Memory in patients with cerebellar degeneration. Neurology 1993;43:1536-44.

46 Silveri MC, Leggio MG, Molinari M. The cerebellum contributes to linguistic production: a case of agrammatic speech following a right cerebellar lesion [see comments]. Neurology 1994;44:2047-50.

47 Allen G, Buxton RB, Wong EC, et al. Attentional activation of the cerebellum independent of motor involvement. Science 1997;275:1940-3.

48 Sengupta JN, Gebhart GF. Gastrointestinal afferent fibers and sensation. In: Johnson LR, ed. Physiology of gastrointestinal tract, 3rd ed. New York: Raven Press, 1994:483-519. 